\title{
Principles of Systems Engineering Management: Reflections from 45 years of spacecraft technology research and development at the Mullard Space Science Laboratory
}

\author{
M. R. Emes*, A. Smith, A. M. James, M. W. Whyndham, R. Leal and S. C. Jackson \\ *Author to whom correspondence should be addressed \\ UCL Centre for Systems Engineering, Mullard Space Science Laboratory, Holmbury St. \\ Mary, Dorking, RH5 6NT, UK, Tel: 01483 204100, m.emes@ucl.ac.uk \\ Copyright (C) 2012 by M R Emes et al. Published and used by INCOSE with permission
}

\begin{abstract}
Based on 45 years of experience conducting research and development into spacecraft instrumentation and 13 years' experience teaching Systems Engineering in a range of industries, the Mullard Space Science Laboratory at University College London (UCL) has identified a set of guiding principles that have been invaluable in delivering successful projects in the most demanding of environments. The five principles are: 'principles govern process', 'seek alternative systems perspectives', 'understand the enterprise context', 'integrate systems engineering and project management', and 'invest in the early stages of projects'. A common thread behind the principles is a desire to foster the ability to anticipate and respond to a changing environment with a constant focus on achieving long-term value for the enterprise. These principles are applied in space projects and have been spun-out to non-space projects (primarily through UCL's Centre for Systems Engineering). They are also embedded in UCL's extensive teaching and professional training programme.
\end{abstract}

\section{Context}

UCL's Department of Space and Climate Physics (Mullard Space Science Laboratory - MSSL) is a world-leading research organization and is the UK's largest university-based space research group. MSSL delivers a broad, cutting-edge science programme, underpinned by a strong capability in space science instrumentation, space-domain engineering, project management and systems engineering. MSSL is far from a typical university department. No undergraduate teaching is undertaken at its main site in Surrey, which has around 150 staff and is configured as an integrated research and development laboratory. Projects undertaken vary from small, $\mathrm{PhD}$ research activity to multi-million dollar developments taking over five years and involving more than twenty people on site and many more in locations around the world. MSSL develops and tests hardware and software, usually as part of an international consortium, with engineers working alongside scientists to ensure that the instruments produced address key questions in modern space science. Post-launch support that is linked to pre-flight and flight calibrations enables scientists to understand the responses of the instrument, greatly benefitting the analysis and interpretation of the data. Since its formation in 1966, MSSL has been involved in more than 35 scientific space missions and over 200 rocket launches, with an excellent record of successful development.

Quality performance metrics. $100 \%$ of MSSL instruments have had a successful development and environmental test programme and have been accepted by the relevant space 
agency; $100 \%$ of MSSL instruments have worked successfully when the spacecraft itself has achieved orbit (and been operational).

Resource performance metrics. The nature of the research and the typical relationship with research councils means that although funds are limited, under certain circumstances extra funds can be made available. Furthermore, MSSL occasionally chooses to partially support instrument developments from internal resources for strategic reasons. For this reason, cost based performance indicators are difficult to use. In general, however, MSSL copes well in a resource-hungry environment.

Schedule performance metrics. While delivery schedules are often negotiated (the norm for the domain) and space agencies typically include margin in this area, MSSL has not been responsible for any major launch delay.

\section{Method}

UCL Centre for Systems Engineering (UCLse) is a university-wide centre of excellence for systems engineering and is hosted within MSSL. For some time, UCLse has been reviewing experiences from MSSL space projects, and in January 2010, a project was undertaken to formally consolidate these experiences to provide a more coherent expression of best practice in project management and systems engineering. Drawing upon post-project interviews with project managers and systems engineers, the focus of the project was an intensive three-day workshop in which UCLse staff and programme managers reviewed the experiences and identified the influences that had made the greatest impact on the outcomes of MSSL projects. From an initial brainstorm of issues, a shortlist of common themes was identified, and from these themes it was found that a set of five orthogonal 'principles' were needed to cover the most important issues. During the workshop the names and an approximate description of the principles were agreed, with the exact wording and further justification for the principles determined progressively in the weeks following the workshop.

Whilst derived from the space domain, it is felt that these principles have generic applicability and are fundamental to the management of systems engineering endeavours; they now provide a coherent vision of the UCLse approach to Systems Engineering and its management. Moreover, UCLse has promoted these principles to good effect through its continuing professional development programme and master's programmes with delegates and students from around the world representing a wide range of sectors.

\section{Results}

\section{Principle 1: Principles govern process}

Statement of principle. Systems engineering and its management is facilitated through the development of processes. However, over-dependence on processes in situations where they do not apply (or are clearly not designed for) can cause problems. Processes should be seen as enabling rather than deterministic: individuals need to be both accountable for their actions and given a level of discretion in the application of high level processes. When adapting a generic process to a particular situation the individual must first understand the principles that underpin the process. Principles should be derived from experience and analysis of past endeavours including development failures. It is essential to capture these lessons and continuously improve current processes. 


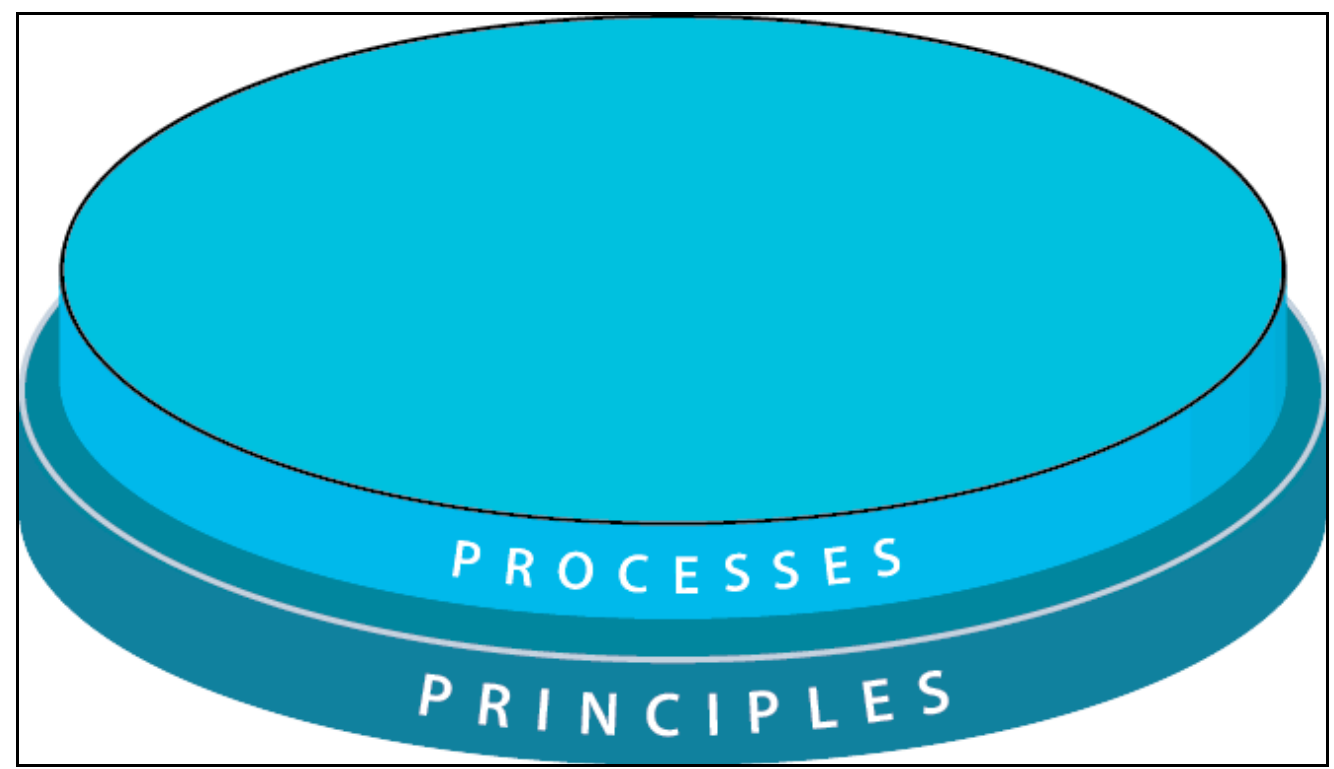

Figure 1. Principles govern process

Justification of principle. When the environment in which we work changes, the old rules no longer apply. When this happens, we rely on underlying principles to guide us. We don't want our systems engineers or even our specialist engineers to become unquestioning cogs in a machine. Engineers are capable of great creativity, and they should be empowered to apply this creativity to processes as well as the products they design. The project team and the organization in which it resides must be a learning organization (Senge 1990), striving for continuous improvement of its processes in the search for quality (Liker 2004).

Processes and standards are valuable, however, to facilitate exchange of information with customers and project partners. Especially in safety-critical systems and demanding environments such as space, very high levels of reliability and quality are essential and standards and common processes help to achieve this. MSSL therefore embraces standards like ISO 9001 (International Organization for Standardization (ISO) 2008), and the European Space Agency's ECSS standards (European Cooperation for Space Standardization 2011). Standards embody the codified knowledge of past generations of expert engineers. If we encouraged all our engineers to challenge standards and processes routinely, we would spend our time forever reviewing techniques rather than applying proven techniques; this would be inefficient at best and dangerous at worst.

What is the right amount of process review to allow? This is analogous to the question 'what is the right amount of tailoring to a process' (INCOSE 2011, 302). The key is to empower 'process innovators' that understand the objectives that different processes are trying to achieve and can bring knowledge or experience to the problem to identify areas for valuable improvement. Sometimes, the best people to suggest improvements will be those experienced in applying the existing process for years - those familiar with the strengths and weaknesses of the current ways of working. Other times, new employees or outsiders (such as consultants) may identify weaknesses with existing practices to which experienced staff have become desensitized.

The process of continuous improvement is applied at MSSL through a review process at the end of every project to reflect on the successes, challenges and areas for improvement in each project. Lessons learnt from these reviews feed back into regular programme review meetings 
attended by all project managers, giving the opportunity for a collective body of knowledge and best practice to develop.

In space projects, environmental qualification of a design is usually an essential part of the development process and involves subjecting a test item to higher levels of stress (such as vibration) than they would expect to experience during launch. Ideally, this would mean building a special item purely for testing and then discarding it, since the testing process may have weakened it. In this way, the design rather than the test item is qualified. To save resource, an increasingly common approach is to move to a 'protoflight' model philosophy where the flight hardware is tested to a lower level, albeit still somewhat above flight levels. In this way, the risk of degradation due to test is reduced and it is now the item rather than the design that is qualified.

On a number of occasions we have seen items fail either the qualification or protoflight qualification tests. The formal process would demand repair and retest, but careful consideration is needed at this point. Repetition of testing could degrade the strength below a flight-acceptable level. Furthermore, such repair would take time and resource, and the consequences of a further failure (due to the weakening) need to be considered. At this point, one should fall back on the principle underlying the testing process - namely that the activity is meant to reduce risk not increase it. Through analysis of the failure and argument that the situation is sufficiently well understood that an alternative course of action is preferable, we have dealt with some very difficult situations. For example, during a protoflight vibration test, several components on a printed circuit board became detached. On analysis it was discovered that all had a common and simple mounting problem. Rather than risk weakening other components with a full retest, the board was repaired and tested at a much lower level with the full agreement of the space agency involved (a second failure would have set the project back two months while a new item was built and tested).

MSSL also looks outside its own projects for sources of inspiration, in the principle of Open Innovation (Chesborough 2003). UCLse and the Technology Management Group at MSSL continuously reviews best practice in Systems Engineering and Project Management and feed this into internal (and external) training courses and programme review meetings.

\section{Principle 2: Seek alternative systems perspectives}

Statement of principle. To enhance understanding it is worthwhile exploring a range of systems perspectives, viewpoints or abstractions, including the additional capability and uncertainty that is uncovered by incorporating humans in systems. Complexity can be managed through a 'divide and conquer' approach, dividing systems into interacting systems elements and understanding the function of those elements, their interactions (both planned and unplanned) and how the elements collaborate to deliver the system's emergent properties. There will be many options for how a system is partitioned - each with different strengths and weaknesses. It is important to recognize the importance of overlapping hierarchies (elements that are parts of more than one system and require appropriate management and control).

The time dimension can be a valuable source of insight. We should note the nature of the solutions to similar problems faced in the past, and recognize technology trends that will influence the next generation of solutions. In a changing world, system developments must accept the need for evolving requirements and include flexibility in delivered systems to adapt to changing needs during the system life. 


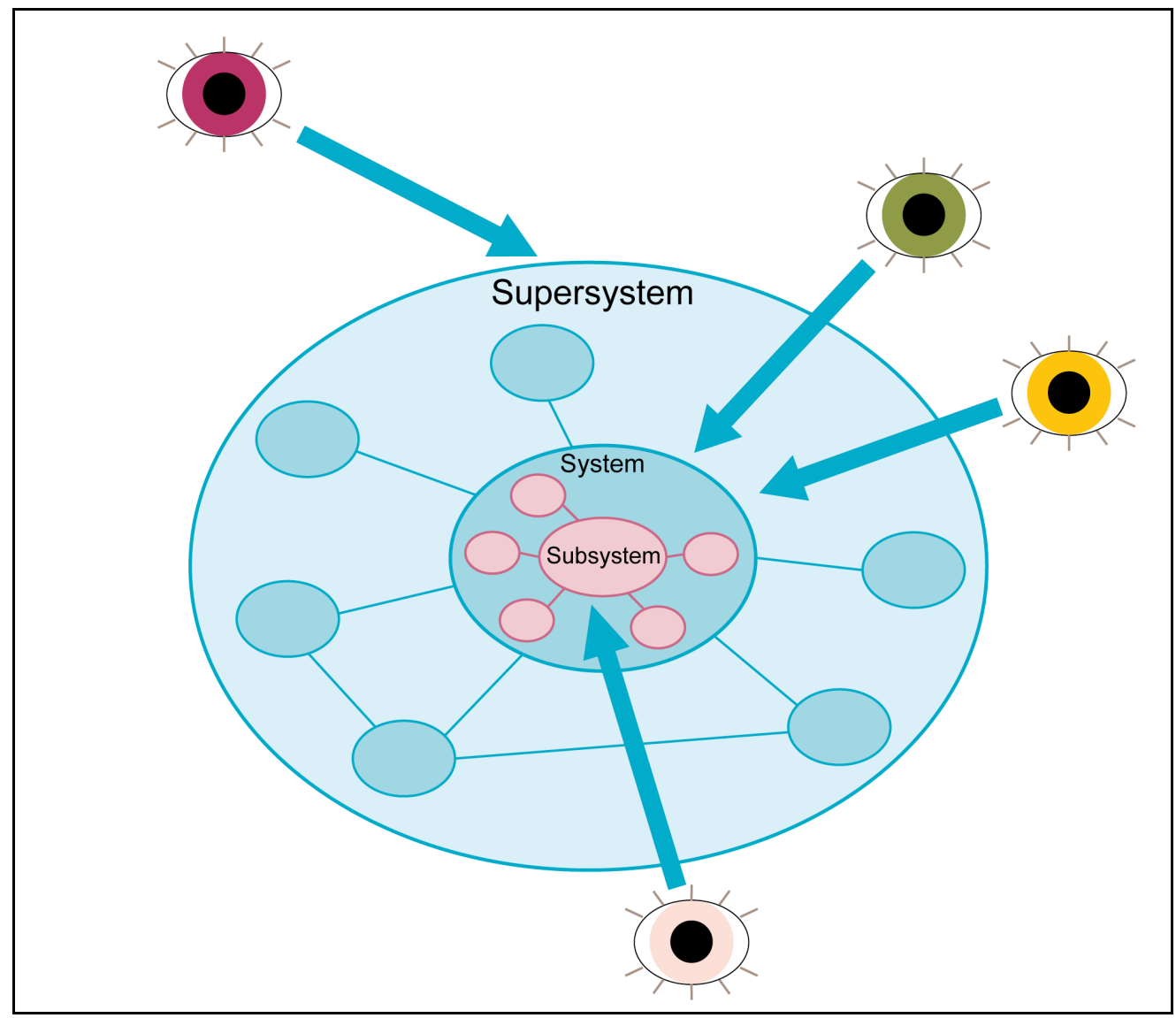

Figure 2. Seek alternative systems perspectives

Justification of principle. Systems are, by definition, more than the sum of their parts (Hitchins 2003). We need to be sensitive to cause and effect and the repercussions (sometimes distant in time and space) of making changes to one part of a complex system (Sterman 2000). Nevertheless, the pragmatic process of developing systems under time constraints requires systems to be partitioned into manageable pieces which can be designed and manufactured by separate groups before being reassembled into a working whole.

Systems can be defined in many different ways, depending on how we partition the system internally and where we draw the system boundary (Martin 2008), and this flexibility should be explored to maximize our understanding of a system. Sometimes we are encouraged to take a single viewpoint when developing a system, and to make sure that from that viewpoint the system's performance is excellent. When designing a car or an aircraft, for example, the needs of the driver or pilot may seem to outweigh all others from a comfort and safety perspective. Or, a market may be so saturated with similar product offerings that the target customer may be quite specific (such as for technical books or some financial products). In other cases, a trend-setting manufacturer may decide to promote a new product in a particular way, promoting some aspect of form or function above all else. In all of these situations, however, the apparent focus on one stakeholder is an illusion.

In reality, all products' designs represent a compromise between offering performance in one dimension and offering performance in another. For many products, from consumer electronics to buildings, this compromise may be most obvious in the distinction between form and function - is it aesthetically appealing, and how well does it meet its functional requirements? In general, the requirements of different stakeholders will conflict, will be uncertain and will 
change over time, not only because their needs change in an unchanging environment, but also because the environment changes owing to technological, economic or political changes. The challenge in multi-criteria decision making like this is to understand how to trade off performance in one dimension against performance in other dimensions in an uncertain environment, with a focus on delivering a valuable system design (Curran et al. 2010).

During a three-year research project investigating technology management in instrumentation supply chains ${ }^{1}$, we developed a method for planning new multi-stakeholder technology developments in which we scored each solution concept according to its effectiveness from the perspective of each stakeholder against each of their requirements, and weighed these against implementation factors of cost, risk and time to deliver (Emes 2007). In this, we incorporated Technology Roadmapping (Phaal et al. 2003) and Scenario Planning (van der Heijden 1996) to help plan for a technology development in an uncertain future. This is valuable whether we are mass-market suppliers of oil like Shell (2011), consumer electronics manufacturers like Samsung (Moeller and Brady 2007, 49), or whether we are responsible for delivering one-off projects such as in the aerospace, defence, construction or IT domains (NASA 1997).

A key challenge is achieving the right balance between fixing requirements to maintain design integrity in a complex system, and allowing flexibility to enable the system to adapt to a changing environment and changing customer requirements. We should try to view a system development project in terms of possible successor projects, and seek to design as much of the system as possible to be reusable (to the extent that this makes sense commercially - the cost of design for reuse should be weighed against the anticipated benefits).

The above principle has informed and shaped our approach to the development of plasma analysers. While such analysers, common in the area of space plasma physics, can be configured in many ways, they generally lead to instruments that weigh around $1-5 \mathrm{~kg}$. By considering trends in space mission drivers, opportunities for re-use in emerging space programmes and new technologies, a programme of miniaturization of analysers was embarked upon with analysers weighing $\sim 0.1 \mathrm{~kg}$ and able to be flown on nanosatellites (with total mass less than $10 \mathrm{~kg}$ ). This programme is now well past its proof-of-concept stage with launches planned on several missions, including a 50-nanosatellite project.

Seeking alternative systems perspectives can be a very creative process, such as embodied by product development firm IDEO's approach to design (Kelley 2001) and can be facilitated by primary research in which important stakeholders are identified and interviewed (both before and after prototype systems are developed - iterative approaches to development are encouraged wherever possible to facilitate this feedback). Both qualitative approaches (such as depth interviews and focus groups) and quantitative approaches (questionnaires to a carefully designed sample of a population of interest) can be useful here. According to research by the Standish Group into IT projects, 'User involvement' is the single most important factor in determining whether a project completes successfully (The Standish Group 1994). Often, customers do not fully understand what their needs are (Workman 1993), both for major one-off projects and for mass-market production (there are many examples of successful products that were created in spite of, rather than because of, market research findings such as the Sony Walkman). This is particularly true for the customers of system integrators. In this

${ }^{1}$ An Intersect Faraday Partnership project sponsored by the UK Engineering and Physical Sciences Research Council, EPSRC and the UK Department for Business Innovation and Skills (formerly the Department for Trade and Industry) 
case, an important output of the system development is establishing a set of value-adding system requirements, and flowing these requirements down in a way sensitive to the needs and capabilities of the supply chain (Emes, Hughes, and Smith 2005; Emes and Smith 2005). Soft systems methodology can be used to good effect to explore multiple worldviews of a system (Checkland 1999; Checkland and Scholes 1999; Wilson 2001) and to develop rich pictures that identify areas of potential conflict.

Seeking alternative systems perspectives can also be a more mechanistic process, in which aspects of a system are considered in a hierarchical sense, such as using hierarchical holographic modelling (Haimes 2009). In each case, assumptions must be identified and challenged to ensure we have the best possible understanding of the system before embarking on a system development. Architecture frameworks such as Zachman (IT/general enterprise architecture), DODAF/MODAF (defence) and TRAK (rail) have been developed to encourage a broad range of perspectives to be considered in a consistent manner between projects in a range of industry sectors. TRAK, for example, has a set of five 'perspectives' (enterprise, concept, procurement, solution and management) each with a number of 'viewpoints' (22 in total). Although the business case is weak for MSSL to adopt a formal architecture framework developed for a different domain, MSSL is exploring the idea of using a basic set of standard viewpoints that encourage different perspectives to be considered; consistent with the idea that 'principles govern process', however, flexibility to explore additional perspectives will be maintained. In parallel, MSSL is taking an interest in the emerging European Space Agency Architecture Framework (Gianni et al 2011).

\section{Principle 3: Understand the enterprise context}

Statement of principle. System developments are undertaken by an organization (usually a business) because they give benefits to that organization. It is essential to understand the organization's objectives and constraints when determining the optimal solution. The system development system (the combination of enterprise, collaborators and supply chain that develops the system solution) has to be configured to make it fit for purpose within whatever constraints exist. Soft systems approaches may be applied to facilitate the accommodation of a systems development project within an organization.

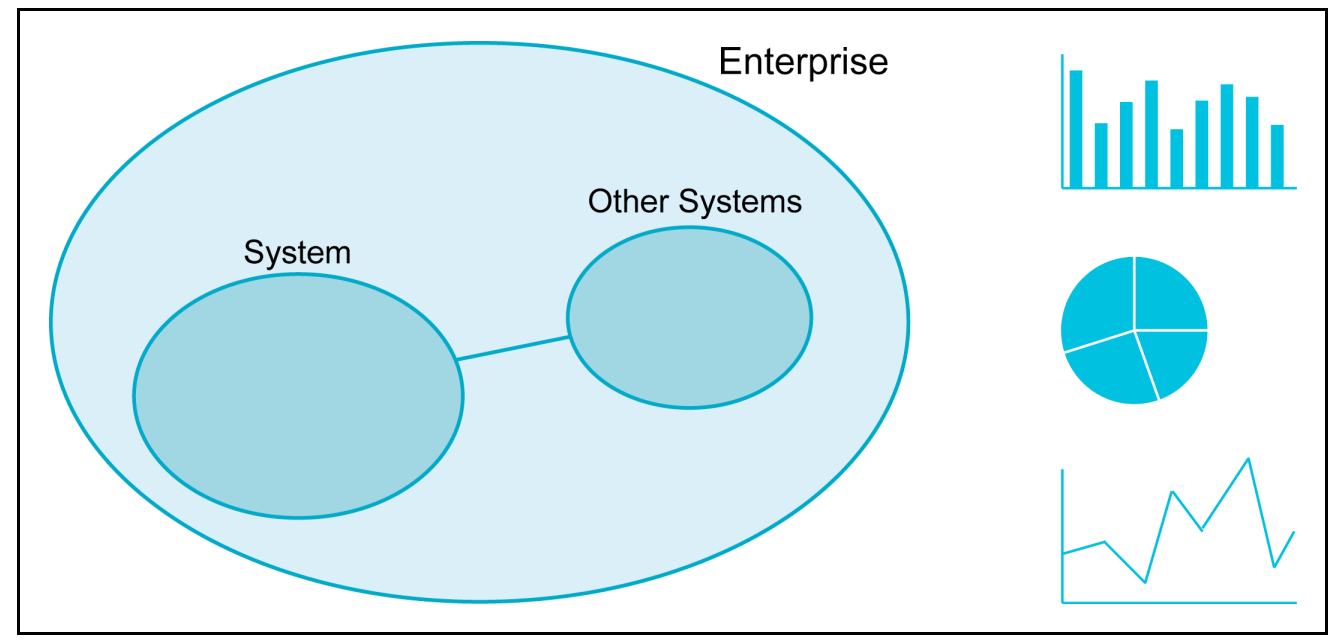

Figure 3. Understand the enterprise context

Justification of principle. Projects create systems, and these projects are subsystems of an enterprise, and therefore need to be sensitive to the needs of the enterprise. Businesses exist to 
create value for their owners (Brealey, Myers, and Allen 2005). For large companies, the owners are usually shareholders. Even most not-for-profit organizations have a primary focus on survival (income exceeds spending) and growth (this is not true for organizations set up for specific short-term projects). A project-based enterprise should be designed or architected to maximize its effectiveness in delivering valuable projects (Giachetti 2010). It is perhaps easy to forget when worrying about design choices in a technical system that every decision will have an impact on the performance of the parent enterprise, and that the design of the enterprise constrains or facilitates the performance of a project. Early or late delivery of projects, delighting or disappointing the customer, inspiring or burning out the project team, and identifying or missing clever ways to reuse technology can all have major implications on an organization's ability to receive income or to spend money (now or in the future).

MSSL is part of a major UK University whose goals include education, research and wider social and economic impact. It is vital that MSSL aligns to these goals; we have therefore embraced them through a number of initiatives including:

- Technology research spun-out to support the UK space industry through subcontracted, specialist engineering

- A masters-level programme of education that is aligned to our research interests

- An outreach programme that encourages future interest in space through the dissemination of our research and technology interests

- A professional training programme in Systems Engineering, Systems Engineering Management and Project Management.

We should also look outside our own enterprises to understand the external environment. What is the competitive landscape, for example? When bidding for a project, what will be the likely competing bids, and how can we maximize our perceived value relative to theirs? For a new product development, how might competitors react? For competitor new product developments, how should we respond? Systems engineering managers in a commercial organization should be alert to the possibility of exploiting technology developed elsewhere, or selling or licensing technology to competing organizations, with at least a basic understanding of the concepts of value-creation, cost-benefit analysis, and intellectual property.

\section{Principle 4: Integrate systems engineering and project management}

Statement of principle. Project management and systems engineering management are highly overlapping endeavours. In both cases, their general scope is the fitness for purpose of the end product and the efficiency of its production. Different organizations define differently the responsibilities of project managers, programme managers, systems engineering managers and chief scientists. Nevertheless, there needs to be cooperation and coherence in the management structure, which recognizes the differing approaches of (systems) engineering and (project) management. While project management is typically based around a deterministic breakdown of the required activities and the creation and delivery of a causal network of such activities against defined timescales, engineering often involves iterative development with concurrent progress across a broad front. This difference can lead to real difficulties when reporting progress. Projects are systems, and need to be managed with a similar blend of science, heuristics (rules of thumb based on lessons learnt and best practice) and creativity. Too often, projects are seen deterministically, when in fact there are major sources of uncertainty (threats 
and opportunities) that could have significant implications for optimisation. The optimum system depends on the project design, and the optimum project design depends on the nature of the system to be delivered. This interdependency between optimum system and optimum project needs to be recognized and managed.

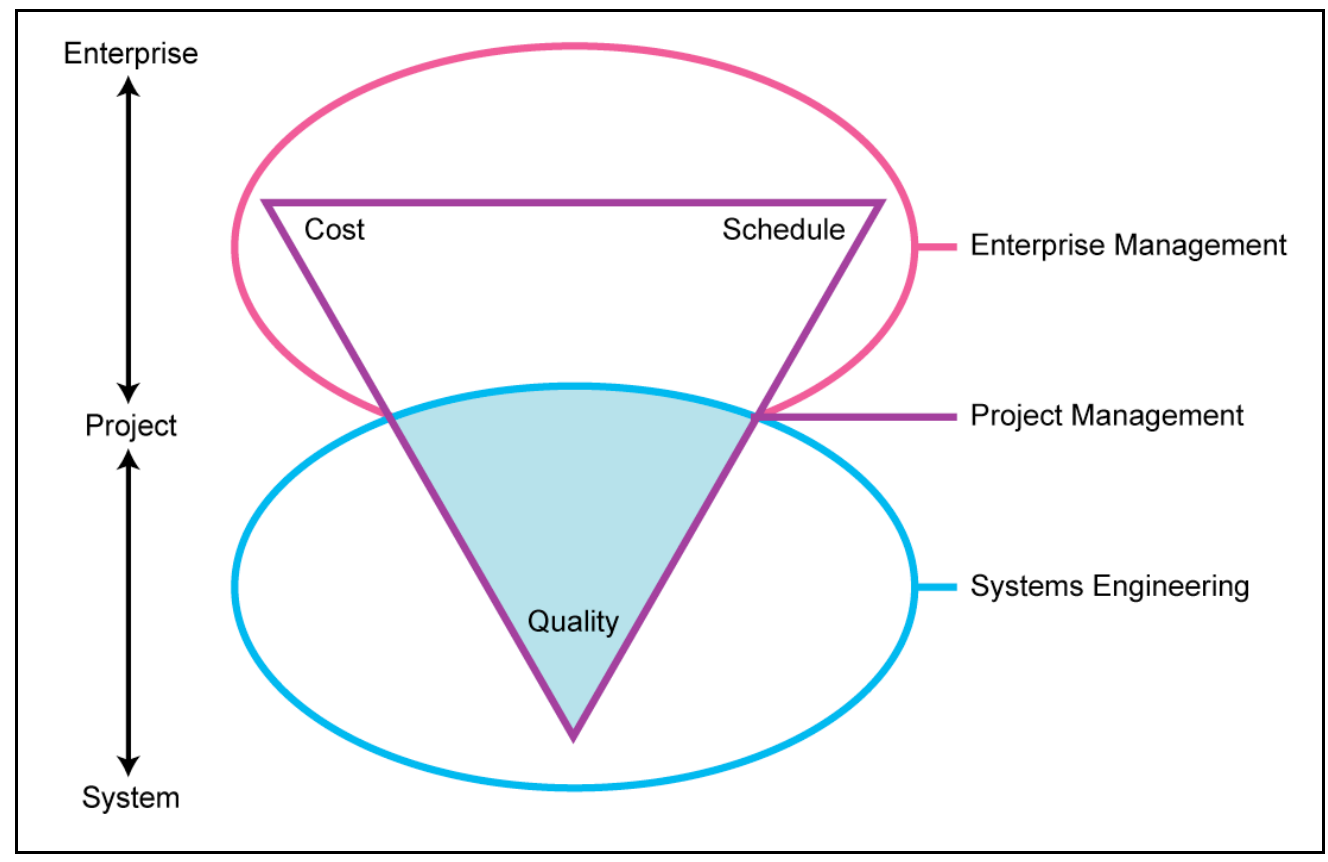

Figure 4. Integrate systems engineering and project management

Justification of principle. The famous project triangle that shows the interplay between Quality, Cost and Schedule considerations gives a useful backdrop for a discussion of the relationship between Systems Engineering and Project Management.

As in Figure 4, we see the Systems Engineering role having a primary responsibility for ensuring that the delivered system or product has the required quality or performance level, with the Project Management role having primary responsibility for ensuring that the project is completed according to the agreed budget and schedule. There is a danger here that both systems engineers and (even more so) project managers have an insular view of the project, and lose sight of the project's role in delivering value to the wider organization. The impact of this can be a willingness to overwork staff and to de-prioritize strategic activities in favour of a greater focus on project work, which may allow the project to be delivered on schedule, but often will not deliver the project on budget if all costs are correctly allocated (such as using activity-based costing to capture the real project costs including the appropriate share of labour, materials, equipment and overheads (Kee 1999)).

There may also be a tendency amongst some project managers to favour visible progress (i.e. manufacturing) at the expense of planning. There should be a symbiotic relationship between the Systems Engineering and Project Management roles, with the systems engineer helping the project manager to understand the implications of budget and schedule decisions on delivered performance, and the project manager helping the systems engineer to understand the implications of technical decisions on overall budget and schedule.

Within MSSL, Systems Engineers and Project Managers work closely in very integrated teams. We largely recruit both from a common pool of either applied space scientists/ 
instrument scientists or space engineers. While responsibilities are well defined, cooperation and support is part of the laboratory's culture. A long and common exposure to space mission lifecycles has meant that a level of 'unconscious competence' has been achieved - reinforced through dialogue, debate and experience.

The relationship between a systems engineer and a project manager is just one example of roles with overlapping interests. At a higher level there is a similar (ideally, but not always, constructive) tension between a project manager (responsible for the quality or performance of a project) and programme managers or senior executives ('Enterprise Management' as shown in Figure 4), who worry about quality or performance of individual projects only insofar as they impact growth and profitability objectives.

It is important to distinguish between an employee and the role fulfilled by an employee at any one time. People with one job title will generally perform multiple roles, and some roles may be shared between multiple people. We researched this link between job title and role in a research project for GlaxoSmithKline's High Throughput Chemistry R\&D facility and found that understanding the relationship between roles is crucial in optimising system developments (Emes, Hughes, and Smith 2005).

\section{Principle 5: Invest in the early stages of projects}

Statement of principle. For any activity in a project there will be a correct time to undertake it. Too early wastes resources while too late can lead to downstream adverse impacts. The optimum ordering of activities should be identified, resisting pressure to defer work until later for short-term reasons. Often this means that a project's ideal resource profile will be reshaped exhibiting an earlier peak (sometimes called 'left shift' of effort), with the expectation that this will lead to a reduction in the total effort required by the project, and a greater chance of project success. This approach can be extended upstream of the project, for instance investing resources in preparing for a future bid or even in predicting customer needs and future technology requirements. Above all, a project should be seen as an investment - it requires resources to be committed early on to deliver a (probabilistic) payoff later on (as major costs are avoided). Like other investments, projects should be seen as part of a portfolio of activities (a programme) that also needs to be optimized holistically. 


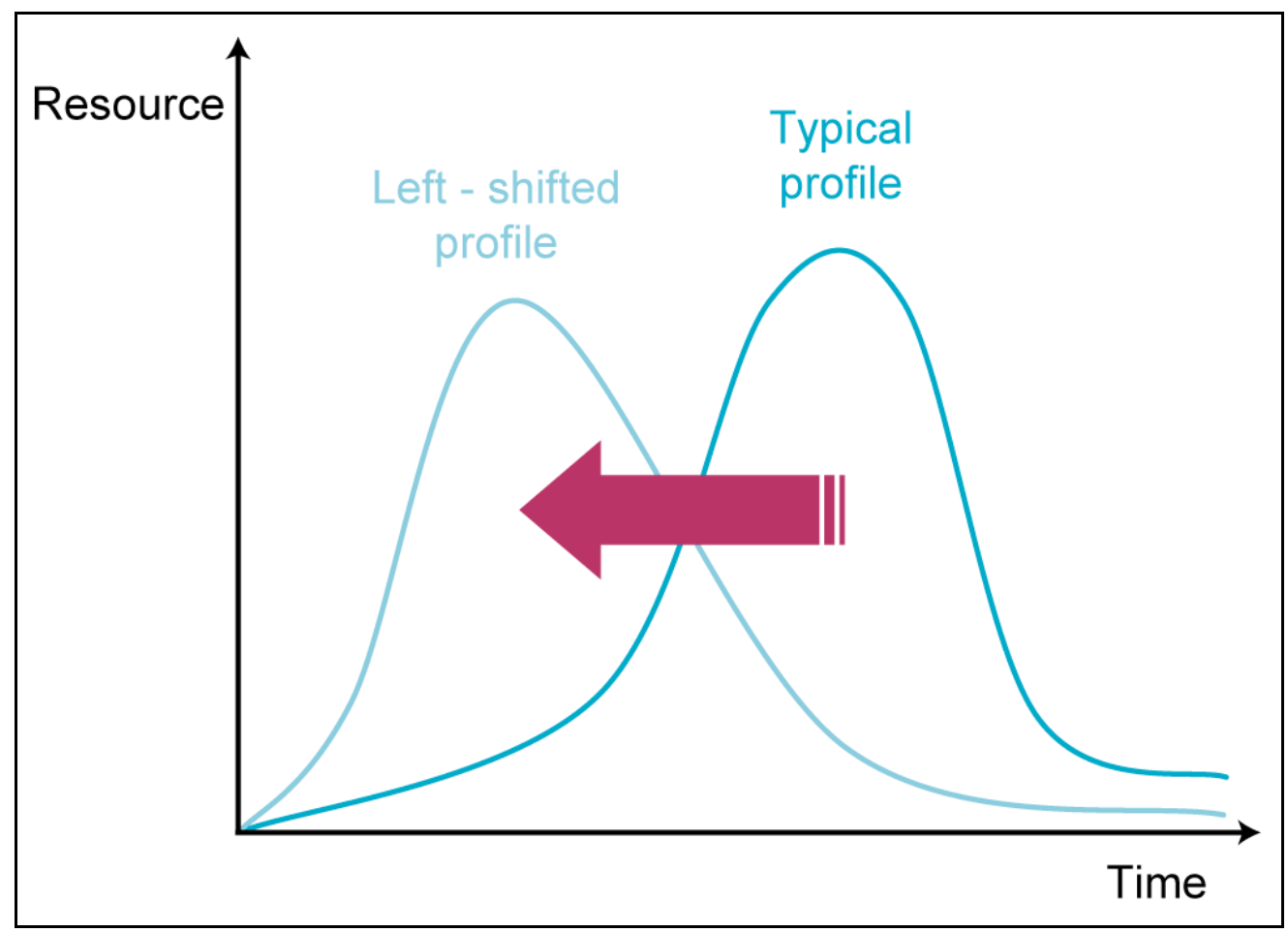

Figure 5. Invest in the early stages of projects

Justification of principle. It can be argued that in the time taken to accrue the first $20 \%$ of actual costs of a project, $80 \%$ of the of the total life-cycle costs are committed (INCOSE 2011, 14-19). It is therefore essential that decisions made in the concept and definition/development phases of projects be made with the benefit of good information and detailed analysis.

The idea of left shifting to invest effort in the early stages of projects will seem like common sense to most systems engineers, but there are many reasons (including some that are sensible) why left-shifting will be resisted by project managers and senior executives (Emes, Smith, and James 2007).

For example, the incentive to invest in the proposal-writing process to ensure that projected costs are accurate is weak - there is a 'conspiracy of optimism' (RUSI 2007, 60). This is because project selection favours those projects that underestimate their costs, and for many major projects failure is not an option once a project is underway so escalation of costs rarely leads to project termination. This problem is exacerbated by 'optimism bias' - the natural tendency to be overly optimistic about the speed at which progress will be made and the likelihood of problems occurring (HM Treasury 2003, 29-30).

Projects should be managed with a focus on achieving value for money (Kerzner and Saladis 2009). What this means in practice depends on the timing and conditions associated with costs incurred and income received and should involve some combination of value engineering (SAVE International 2011) and application of lean principles to avoid waste (Rebentisch, Rhodes, and Murman 2004). The value of investment is probabilistic in that there is no guarantee that increased cash flow will follow. Sometimes, such as when consortium building, the value to be obtained from early investment is primarily derived from an increased probability of winning a contract to supply a system; this value may never manifest. But even here, the consortium-building process may lead to valuable follow-on opportunities with project partners. Other times, the value may be derived from a reduced risk of project failure; 
more thorough planning can help to anticipate many problems that would normally be encountered in manufacturing or, worse, in service. It is difficult to retrospectively justify expenditure on the basis of avoidance of failure, but just as with insurance, the value is real. Long-run investment in capability ensures that when projects start, the tools and knowledge at the project team's disposal allow progress to be made relatively quickly.

The cost of space science missions can be very large (typically in excess of $\$ 500 \mathrm{~m}$ ) and can increase very significantly in the face of unforeseen technical difficulties. In order to ensure appropriate technical maturity across the lifecycle ESA (European Space Agency) and NASA gate their development process with the use of Technology Readiness Levels (TRLs). While this provides a useful check on the latter end of the process, it actually adds relatively little to what was already a well-understood process. However, it has had a particular impact upon the earlier stages, especially at the point of mission commitment where TRLs are expected to be greater than 5. MSSL needs to bring forward compelling and enabling technologies to a level of maturity that are of sufficient maturity to be selectable in a future mission. This involves often a very long-term programme of technological development targeted at key issues and designed to remove risk before commitment to a particular mission.

Our goal for some years has been to develop cryogenic coolers able to provide the very low temperatures demanded by state-of-the-art photon sensors. Our preferred technology is adiabatic demagnetization refrigerators, which involve a complex configuration of paramagnetic elements, superconducting magnets, heat switches and thermal isolation. These need to be able to operate continuously in space and able to survive the stresses of a launch. The challenge has been considerable (not least the challenge of convincing our peers of its credibility), but through a process of innovative system design, modelling, and identification and prioritization of technical issues, we have been able to space qualify such a cooler and are now undertaking a programme of mass reduction. We believe we are now ready to propose a flight instrument for the next generation of space science missions.

The appropriate amount to invest in systems engineering and in the definition stages of projects in general will depend on the circumstances of the project. Whilst research into NASA projects suggested around $15 \%$ of project budget should be spent on the definition phase (Gruhl 1992), the most cost-effective activities to be undertaken in this phase, and the broad applicability to organizations of different sizes and maturities (and in different sectors) needs further investigation.

\section{Conclusions}

By reflecting on its experiences in managing spacecraft technology projects over the last 45 years, MSSL has established a set of principles that capture the most important lessons learnt. These principles help to structure the way systems engineering and project management are practised in the development of spacecraft technology at MSSL; they also give an important focus to the way UCLse educates systems engineers through its MSc programme and industrial training contracts. The latter are proving a useful test-bed for validating the principles. When delegates across a broad range of industries are asked to list the challenges they face when delivering projects (before being introduced to the principles), they almost always produce a subset of the issues addressed by the principles. When the principles are later introduced, they therefore resonate. 
The Standish Group's (1994) Chaos Report into (software) project failure identified through market research ${ }^{2}$ a number of key factors that contributed to the success of a project. The most important factors were user involvement, executive management support, clear statement of requirements, and proper planning. The most significant determinants of project cancellation were the above success factors, a lack of resources or unrealistic expectations. Of the five principles described in this paper, only the first - principles govern process - does not directly address the key factors described by the Standish Group research. Yet one of the strongest conclusions of the Chaos Report was that software projects failed because their managers did not learn from their mistakes and seek to improve their processes - exactly the point of the first principle.

The integrating theme behind the principles is the desire to foster an ability to anticipate and respond to a changing environment with a constant focus on achieving long-term value for the enterprise. This value will primarily be associated with superior project performance, whether it be through increased performance of the delivered system (and therefore increased stakeholder utility), reduced development cost, reduced development time or reduced risk that one of the other three criteria will stray outside acceptable limits. We must not neglect, however, the value to the business of factors beyond the project, such as corporate reputation, opportunities for economically attractive follow-on projects, and the development of technological capabilities and a skilled and motivated workforce.

The relationship between the principles is expressed in Figure 6 below. UCLse will continue to monitor MSSL's projects and the extent to which the principles contribute to better outcomes, both within MSSL and in other organizations. Note that the Director of MSSL has been heavily involved in the process of developing the principles, and his advocacy will help promote the continued application of the principles in MSSL projects. Other organizations seeking to establish principles for how they manage systems engineering efforts will benefit greatly from similar high-level buy-in.

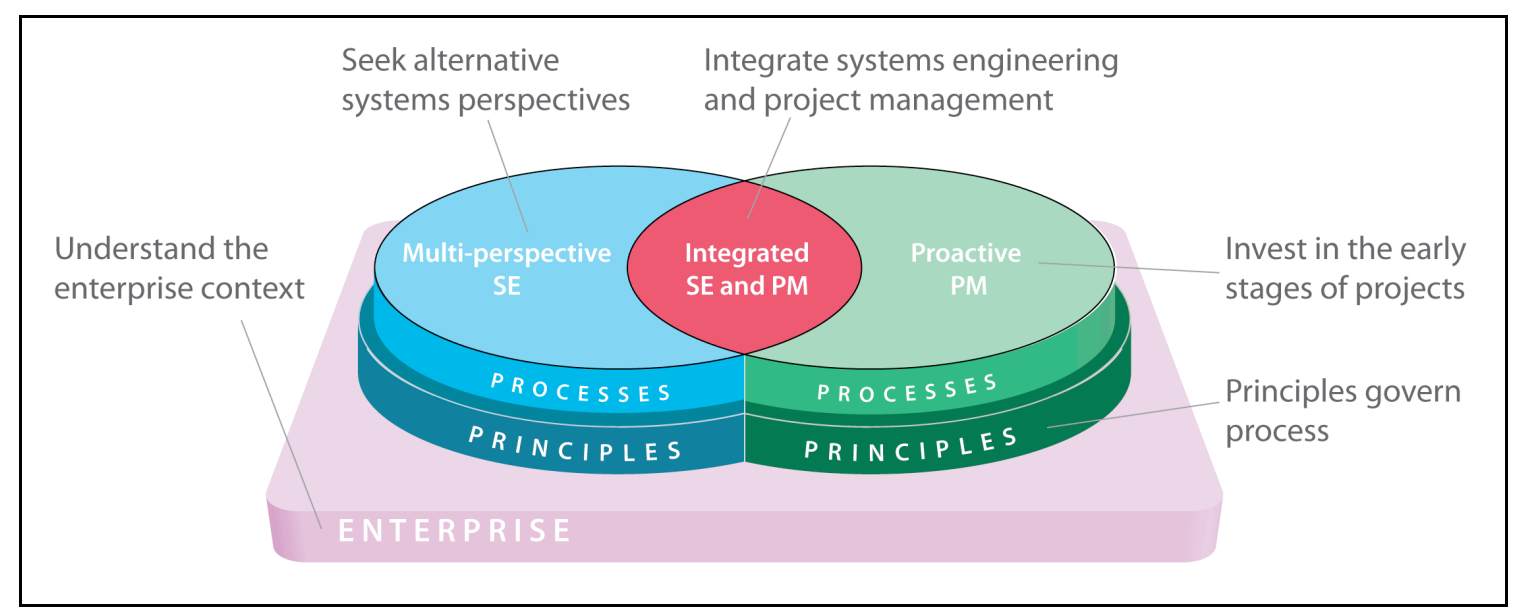

Figure 6. Relationship between the principles

\section{References}

Brealey, R. A., S. C. Myers, and F. Allen. 2005. Corporate Finance. 8th Edition (International Edition) ed. New York: McGraw Hill.

\footnotetext{
${ }^{2}$ The Standish Group survey was responded to by 365 IT executive managers representing a total of 8380 project experiences
} 
Checkland, P. 1999. Systems Thinking, Systems Practice. Chichester: Wiley.

Checkland, P., and J. Scholes. 1999. Soft Systems Methodology in Action. Chichester: Wiley.

Chesborough, H. W. 2003. Open Innovation: The New Imperative for Creating and Profiting from Technology. Boston: Harvard Business School Press.

Curran, R., T. Abu-Kias, M. J. F. Repco, Y. L. J. Sprengers, P. N. C. S. van der Zwet, and W. Beelearts. 2010. A Value Operations Methodology for Value Driven Design: Medium Range Passenger Airliner Validation. In 48th AIAA Aerospace Sciences Meeting Including the New Horizons Forum and Aerospace Exposition. Orlando FL.

Emes, M. R. 2007. "Strategic, Multi-Stakeholder Trade Studies." INCOSE Insight no. 10 (1):17-23.

Emes, M. R., I. Hughes, and A. Smith. 2005. Internal Invention, External Development. In R\&D Management Conference. Pisa.

Emes, M. R., and A. Smith. 2005. Introducing new technologies in farming - Getting it right second time. In International Council on Systems Engineering UK Spring Conference. Swindon.

Emes, M. R., A. Smith, and A. M. James. 2007. Left-Shift vs The Time Value of Money: Unravelling the Business Case for Systems Engineering. In International Council on Systems Engineering UK Spring Conference. Swindon.

European Cooperation for Space Standardization. 2011 [cited 06/11/2011. Available from http://www.ecss.nl/.

Giachetti, R. E. 2010. Design of Enterprise Systems. Boca Raton FL: CRC.

Gianni, G., N. Lindman, J. Fuchs, and R. Suzic. 2011. Introducing the European Space Agency Architectural Framework for Space-based Systems of Systems Engineering. In Complex Systems Design and Management. Paris.

Gruhl, W. 1992. Lessons Learned, Cost/Schedule Assessment Guide. NASA Comptroller's Office.

Haimes, Y. Y. 2009. Risk modeling, assessment, and management. Third ed. Hoboken NJ: Wiley.

Hitchins, D. K. 2003. Advanced systems thinking, engineering and management. Norwood MA: Artech House.

HM Treasury. 2003. The Green Book: Appraisal and Evaluation in Central Government. London: TSO.

INCOSE. 2011. Systems Engineering Handbook. edited by C. Haskins.

International Organization for Standardization (ISO). 2008. ISO 9001: Quality Management Systems - Requirements.

Kee, R. C. 1999. "Using economic value added with ABC to enhance production-related decision making." Journal of Cost Management (December):3-15.

Kelley, T. 2001. The Art of Innovation. London: Profile.

Kerzner, H., and F. P. Saladis. 2009. Value-driven project management. Hoboken NJ: Wiley.

Liker, K. 2004. The Toyota Way: 14 Management Principles from the World's Greatest Manufacturer. New York: McGraw Hill.

Martin, J. N. 2008. "Using the PICARD Theory of Systems to Facilitate Better Systems Thinking." INCOSE Insight no. 11 (1):37-41.

Moeller, S., and C. Brady. 2007. Intelligent M\&A: Navigating the Mergers and Acquisitions Minefield. Chichester: Wiley.

NASA. 1997. Maintaining U S leadership in aeronautics : scenario-based strategic planning for NASA's aeronautics enterprise: National Academy Press. 
Phaal, R., C. Farrukh, R. Mitchell, and D. Probert. 2003. "Starting-up roadmapping fast." Research-Technology Management no. 46 (2):52-58.

Rebentisch, E., D. H. Rhodes, and E. Murman. 2004. Lean Systems Engineering: Research Initiatives in Support of a New Paradigm. In Conference on Systems Engineering Research. University of Southern California, Los Angeles CA.

RUSI. 2007. The Conspiracy of Optimism. RUSI Defence Systems, October, 60-65.

SAVE International. 2011 [cited 07/11/11. Available from http://www.value-eng.org/.

Senge, P. M. 1990. The Fifth Discipline: Art and Practice of the Learning Organization. New York: Doubleday.

Shell. Looking ahead: scenarios 2011 [cited 06/11/2011. Available from http://www.shell.com/scenarios/.

Sterman, J. D. 2000. Business Dynamics: Systems Thinking and Modeling for a Complex World. Boston MA: Irwin McGraw-Hill.

The Standish Group. 1994. The Chaos Report.

van der Heijden, K A. 1996. Scenarios: The Art of Strategic Conversation. Chichester: Wiley. Wilson, B. 2001. Soft Systems Methodology: Conceptual Model Building and its Contribution. Chichester: John Wiley \& Sons Ltd.

Workman, J. P. 1993. "Marketing's Limited Role in New Product Development in One Computer Systems Firm." Journal of Marketing Research no. 30 (4):405-421.

\section{Biography}

Dr. Michael Emes is Head of the Technology Management Group at MSSL and Co-director of UCLse. He researches technology management tools and theory, risk management, modelling, and the intersection of systems engineering and management. He teaches postgraduate courses at UCL and industrial training courses in the areas of systems engineering, design, modelling and management and is Programme Director for the MSc in Systems Engineering Management. Before joining UCL, Michael was a strategy consultant working on projects in retail, e-commerce and transport. He has a first-class MEng in Engineering, Economics and Management from St. John's College, Oxford, and a PhD in Spacecraft Engineering from UCL.

Professor Alan Smith started as an instrument scientist for the Medium Energy X-ray Experiment which flew on-board the European space agency mission EXOSAT. In 1990 he joined MSSL, initially as Head of Detector Physics but later to become Programme Manager and eventually Director and Head of Department and vice-Dean for Enterprise. In 1998 he was made a Professor of Detector Physics. While at UCL he has been Director of UCL's Centre for Advanced Instrumentation Systems, a Co-director of the Smart Optics Faraday Partnership and is founding Director of the Centre for Systems Engineering (1998-present).

Dr. Raúl Leal is the Business Development Manager for the Technology Management Group at MSSL. His academic interests are in systems engineering, modelling and estimation. He has taught for twelve years at postgraduate and undergraduate levels with positions in Mexico, at Kings College London and now UCL. Dr. Leal has over six years experience doing consultancy and training for industry and now he also is in charge of promoting the work of the Technology Management Group.

Dr. Adrian James is a Senior Research Fellow at MSSL and Co-director of UCLse. He has worked at UCL for more than twenty years on various space programmes, including Mars 96, Cluster, XMM Newton, Hinode, and is currently systems engineer for the VIS instrument on the ESA Euclid project. As well as his project management and systems engineering activities within the Department, Dr James provides training courses to industry on various aspects of 
Systems Engineering and Project Management.

Matthew Whyndham is a practising project manager and research scientist at MSSL. Most of his work, both as a scientist and a manager, has been in the instrumentation field (radiation detectors and data handling systems). He has additional experience in software-oriented and research projects. He is the Course Organizer for the Department's MSc programmes, in Systems Engineering Management and in Space Science/Space Technology. He teaches topics in space technology, technology management and project management within these programmes, and is a lead tutor in UCL's APM accredited project management course.

Simon Jackson is a Project Manager in the Technology Management Group at MSSL. He has significant practical experience of project management and has been lecturing in the subject for the last eight years. He spent 20 years working in the defence industry at Rolls-Royce and British Aerospace on several systems engineering projects including the development of military engines, developments of the Harrier and Sea Harrier aircraft and the establishment of aircraft support systems. He has managed several change projects including the development of new resource management systems, new project control systems, quality and process improvement initiatives. 